\title{
Diabetes Mellitus and Dental Health in Children: A Review of
} Literature

\author{
Rafif A Mandura ${ }^{1}$, Omar A El Meligy ${ }^{2}$, Moaz H Attar ${ }^{3}$, Rana A Alamoudi ${ }^{4}$
}

\begin{abstract}
Aim and objective: To illustrate the most important general findings significant for dentists dealing with pediatric diabetic patients, as well as the effect of type 1 diabetes mellitus (T1DM) on children's oral health.

Background: Type 1 DM is considered to be the most popular type of diabetes in children and adolescents which has a strong impact on their lifestyle. Diabetes mellitus (DM) mainly affect organs and tissues that are affluent with blood vessels including kidneys, eyes, and nerves. Adding to that oral cavity is covered with epithelial tissues that are rich with small blood vessels.

Materials and methods: An electronic search of English scientific papers was accomplished using PubMed, Google Scholar, and King Abdulaziz University digital library. Search terms used were children, DM, dental health, gingival health, oral hygiene, periodontal health, and teeth eruption.

Review results: Thirty-six articles were obtained from the electronic search and references of selected studies. In addition, other references were included from selected studies about DM and its relationship to oral health. Multiple studies confirmed that T1DM has a negative impact on oral hygiene, gingival and periodontal health, and teeth eruption. While other studies contradict these results.

Conclusion: There are contradictory studies regarding the effect of T1DM on oral health in children and adolescents. Well-established highquality research with clear and concise materials and methods are required to have representative results.

Clinical significance: Studying the effect of T1DM on oral health in children and adolescents is indicated to set well-established guidelines to reach a high standard of care for those children.
\end{abstract}

Keywords: Children, Dental health, Diabetes mellitus, Gingival health, Oral hygiene, Periodontal health, Review, Tooth eruption. International Journal of Clinical Pediatric Dentistry (2021): 10.5005/jp-journals-10005-2006

\section{INTRODUCTION}

Diabetes mellitus (DM) is considered to be a group of metabolic disturbances that are depicted as hyperglycemia secondary to disturbed insulin secretion or insulin function or both. ${ }^{1-4}$ The cause of metabolic defect of carbohydrate, protein, and fat in diabetic patients is insufficient action of insulin on them. There are specific genetic and environmental factors that might have an influence on B-cells destruction and can increase the risk of the disease, but the main reason for diabetes is still not clear. ${ }^{5}$

There are multiple notable symptoms of hyperglycemia such as polyuria (abnormally increased production of urine), polydipsia (abnormally increased thirst), loss of weight, polyphagia (increased appetite), reduced sharpness of vision, growth deficiency, and increased infections. Chronic hyperglycemia can be associated with ketoacidosis or non-ketotic hyperosmolar syndrome which are life-threatening conditions. In addition, multiple diseases can result from longstanding uncontrolled diabetes that include retinopathy which can lead to vision loss, nephropathy which can cause kidneys damage, neuropathy which in turn can result in foot resection, cardiovascular diseases, and sexual problems. ${ }^{5}$ Type 1, type 2, gestational, monogenic, and other types are considered to be the types of DM, but the most common types are type 1 and type $2 .^{3-5}$

Type 1 diabetes mellitus (T1DM) or insulin-dependent diabetes was known to be a chronic autoimmune disorder. It is considered an immune-associated or immune-mediated disease. ${ }^{5,6}$ On the other hand, T1DM is no longer considered children and adolescents' disease, adult individuals can also be diagnosed with T1DM.
1,3,4Pediatric Dentistry Department, Faculty of Dentistry, King Abdulaziz
University, Jeddah, Kingdom of Saudi Arabia
2Pediatric Dentistry Department, Faculty of Dentistry, King Abdulaziz
University, Jeddah, Kingdom of Saudi Arabia; Pediatric Dentistry and
Dental Public Health Department, Faculty of Dentistry, Alexandria
University, Alexandria, Egypt

Corresponding Author: Omar A El Meligy, Pediatric Dentistry Department, Faculty of Dentistry, King Abdulaziz University, Jeddah, Kingdom of Saudi Arabia; Pediatric Dentistry and Dental Public Health Department, Faculty of Dentistry, Alexandria University, Alexandria, Egypt, Phone: +966-12-6952000 (Ext.: 22306), e-mail: omeligy@kau. edu.sa

How to cite this article: Mandura RA, El Meligy OA, Attar MH, et al. Diabetes Mellitus and Dental Health in Children: A Review of Literature. Int J Clin Pediatr Dent 2021;14(5):719-725.

Source of support: Nil

Conflict of interest: None

There are specific triad symptoms that are associated with the onset of T1DM which are polydipsia, polyphagia, and polyuria. ${ }^{7}$

Multiple oral signs and symptoms can be discovered in diabetic patients including low salivary flow rate, dental decay, gingival and periodontal diseases, oral lesions such as candidiasis and oral lichen planus, burning sensation, altered taste, geographic and fissured tongue, and impaired wound healing..$^{8-10}$ There are contradictory studies regarding the oral health status of diabetic children in

(c) The Author(s). 2021 Open Access This article is distributed under the terms of the Creative Commons Attribution 4.0 International License (https://creativecommons. org/licenses/by-nc/4.0/), which permits unrestricted use, distribution, and non-commercial reproduction in any medium, provided you give appropriate credit to the original author(s) and the source, provide a link to the Creative Commons license, and indicate if changes were made. The Creative Commons Public Domain Dedication waiver (http://creativecommons.org/publicdomain/zero/1.0/) applies to the data made available in this article, unless otherwise stated. 
comparison to healthy individuals. Also, many studies reported that T1DM affects teeth shedding and eruption. Many studies reported that diabetes can cause teeth eruption acceleration and other studies contradict these claims. ${ }^{11-13}$ This review article aimed to illustrate the most important general findings regarding dentists dealing with pediatric diabetic patients, as well as the effect of T1DM on children's oral health.

\section{Materials and Methods}

An electronic search of English scientific papers was accomplished using PubMed, Google Scholar, and King Abdulaziz University digital library. Search terms used were children, DM, dental health, gingival health, oral hygiene, periodontal health, and teeth eruption.

\section{Review Results}

Thirty-six articles were obtained from the electronic search and references of selected studies. In addition, other references were included from selected studies about DM and its relationship to oral health. Multiple studies confirmed that T1DM has a negative impact on oral hygiene, gingival and periodontal health, and teeth eruption. While other studies contradict these results.

\section{Discussion}

\section{Classification of Diabetes Mellitus}

There are several types of DM. Type 1: which is an autoimmune disease caused by the destruction of $ß$-cells that cause an absence of insulin secretion, Type 2: which is a multifactorial disease that occurs due to genetic and environmental defects, gestational: which is the hyperglycemia that occurs during pregnancy, monogenic: which is autosomal dominant disease that causes genetic abnormality in $ß$-cells, and other types: including but not limited to a genetic defect of $ß$-cells function, diseases of the exocrine pancreas, endocrinopathies, drug or chemical induced, infections, uncommon forms of immune-mediated diabetes. ${ }^{3-5}$ Generally, type 1 and type 2 are considered the two main groups of DM. Type 1 DM can occur with a complete absence of insulin secretion. Diagnosis of T1DM is mainly done by serology and genetic tests. ${ }^{5}$

On the other hand, T2DM which is more common than type 1 (represent $90 \%$ of all diabetic patients) occur in people who have an impediment in insulin action and disruption in compensative insulin secretory response. The increased glucose level in T2DM even before arising any signs and symptoms of diabetes can cause abnormality in specific tissues. Throughout this symptomless phase, investigation of abnormality of carbohydrate metabolism can be done using several types of tests such as fasting plasma glucose test, oral glucose tolerance test, or hemoglobin A1c test $(\mathrm{HbA1c}){ }^{3,5}$

Distinguishing between type 1, type 2, and monogenic diabetes is not that easy in all cases, in some cases differentiation between these types of diabetes is considered difficult especially discriminating between type 1 and 2 diabetes. About $5-15 \%$ of T1DM patients are misdiagnosed with T2DM, leading to a faulty rating of T1DM. ${ }^{7}$ Despite that, many clinical features can facilitate the determination of the type of the disease such as the onset of the disease, weight of the patient, presence of autoantibodies, detection of C-peptide, insulin formation, and genetic factors as summarized in Table 1. ${ }^{4}$ Many other studies mentioned that the time elapsed between the diagnosis and the need of an individual to use insulin could indicate the type of DM. In other words, individual with T1DM mostly needs to use insulin in $<1-2$ years. ${ }^{4,14}$ The study suggested that detection of specific biomarkers such as anti-glutamic acid decarboxylase (GAD) or anti-islet cell (ICA) autoantibodies and the rapid need for insulin supplements are other indicators of T1DM. In some difficult cases, when differentiation between type 1 and 2 diabetes is not easy, finding 1 or more autoantibodies biomarkers indicate that the patient has T1DM, but cannot find the biomarkers does not exclude T1DM. ${ }^{4}$ Type 1 diabetic patients are more susceptible to other types of autoimmune diseases such as Graves' disease, Hashimoto's thyroiditis, Addison's disease, vitiligo, celiac sprue, autoimmune hepatitis, myasthenia gravis, and pernicious anemia. ${ }^{5}$

In addition, there are multiple features of T1DM which are the existence of accessory cells on the pancreas, existence of particular autoantibodies, modifications that occur in T-cells specifically in a cluster of differentiation 4 (CD4), reaction to immunotherapy, as well as multiple exposures to different types of autoimmune diseases or in the existence of autoimmune diseases in other persons in the family member. ${ }^{3}$

\section{Incidence and Prevalence of Diabetes Mellitus}

Worldwide, in 2013 around 382 million individuals were diagnosed with DM (type 1 and 2) and the predictions of new cases can reach 592 million in 2035 . $^{15}$

To evaluate the incidence and prevalence of T1DM, classification of the extent of the disease was done as extremely low (incidence of T1DM is $<1$ per 100,000 individual yearly), low (incidence of T1DM is 1-4 per 100,000 individual yearly), intermediate (incidence of T1DM is 5-9.99 per 100,000 individual yearly), high (incidence of T1DM is 10-19.99 per 100,000 individual yearly), and extremely high (incidence of T1DM is $>20$ per 100,000 individual yearly). ${ }^{16}$

In the United States, there are about 26.9 million individuals diagnosed with DM, which represents $8.2 \%$ of the United States

Table 1: Clinical features of types of diabetes mellitus

\begin{tabular}{|c|c|c|c|c|c|c|}
\hline Types of diabetes & Onset of the disease & $\begin{array}{l}\text { Weight of the } \\
\text { patients }\end{array}$ & $\begin{array}{l}\text { Presence of } \\
\text { autoantibodies }\end{array}$ & $\begin{array}{l}\text { Detection of C- } \\
\text { peptide }\end{array}$ & Insulin secretion & Genetic factor \\
\hline Type 1 & $<25$ years (mostly*) & Low & Present & $\begin{array}{l}\text { Absent or minimal } \\
\text { level }\end{array}$ & Lack & $\begin{array}{l}\text { Only in } 5-10 \% \text { of } \\
\text { the patients }\end{array}$ \\
\hline Type 2 & $\geq 25$ years & Obese & Not present & $\begin{array}{l}\text { Average to moder- } \\
\text { ate level }\end{array}$ & $\begin{array}{l}\text { Present in most } \\
\text { cases }\end{array}$ & $\begin{array}{l}\text { In } 90 \% \text { of the } \\
\text { patients }\end{array}$ \\
\hline Monogenic & $\leq 6$ months & Average & Not present & Normal level & $\begin{array}{l}\text { Present in most } \\
\text { cases }\end{array}$ & $\begin{array}{l}\text { Present (autosomal } \\
\text { dominant) }\end{array}$ \\
\hline
\end{tabular}

*But can be discovered at any age after 6 months of life 
population. Around 210,000 children or adolescents younger than 20 years have diabetes, 187,000 of them have T1DM specifically. Adding to that, T1DM showed an increase during the period between 2002 and 2015. Hispanic children and adolescents had the major incidence of T1DM in the period between 2002 and 2020 in the United States, while the period between 2011 and 2015 the majority of T1DM was discovered in non-Hispanic Asian children. Between 2014 and 2015, the annual number of new cases of T1DM in the United States was around 18,291 youths. ${ }^{17}$

A study showed that the recent environmental changes in many countries are one of the major causes of the increased incidence of T1DM in these countries. Getting a luxurious lifestyle has decreased pathogens exposure leading to more autoimmune disease susceptibility. ${ }^{15}$

Generally, there are noticeable variations of T1DM incidence between countries. ${ }^{15}$ The rate of appearance of T1DM is affected by geographic location., 75 A study done by Patterson et al. showed that Europe especially Finland and Sardinia along with North America regions are the top countries that recorded T1DM worldwide. ${ }^{18}$ In Finland, $>60$ cases of the disease were recorded in every 100,000 individuals per year. While about 40 cases in every 100,000 individuals per year were recorded in Sardinia., ${ }^{715,19}$ World Health Organization (WHO) reported that the rate of incidence of T1DM in Finland and Sardinia is around 36.5 in every 100,000 individuals yearly. ${ }^{20}$

In contrast, T1DM is considered a rare disease in China, India, and Venezuela, which recorded only 0.1 individuals per year in every 100,000 individuals. $7,15,20$

World Health Organization stated that T1DM is very common in Arab regions especially in Gulf counties, ${ }^{20}$ specifically in Kuwait and Saudi Arabia. ${ }^{21}$ World Health Organization classified gulf counties as an intermediate to very high in terms of having T1DM. ${ }^{20}$ Kingdom of Saudi Arabia (KSA) is considered to be the largest country in the Middle East. According to that, the incidence and prevalence of T1DM in KSA are considered high. ${ }^{16}$ Type $1 \mathrm{DM}$ is considered an epidemic disease in Saudi Arabia. ${ }^{22}$ Incidence of T1DM in Saudi Arabia increased in the last three decades. ${ }^{16,19,21}$ The result of the study that was conducted in 2008 showed that the prevalence of T1DM in Saudi Arabia in 13 different health sectors was 109.5 in every 100,000 individuals. ${ }^{23}$ In 2010, a study was done by Abduljabbar et al. showed that the incidence of T1DM in Saudi Aramco Medical Services Organization, Dhahran, Saudi Arabia was high with a range of 27.5/100,000 individuals for every year. ${ }^{24}$ Another study was done in Al-Madinah city by Habeb et al. in 2011 concluded that the rate of Saudi individuals who were diagnosed with T1DM was on average of 29 individuals in every 100,000 people. ${ }^{25}$ International Diabetes Federation (IDF) documented that KSA considered one of the ten top countries that have the highest incidence and prevalence of T1DM. ${ }^{26}$ The center of Saudi Arabia is considered the major region of incidence and prevalence of T1DM. ${ }^{16}$ A study in 2015 by Al-Rubeaan reported that individuals who live in rural areas have lesser prevalence and incidence of T1DM compared to individuals living in urban areas. For example, in European countries, symptoms appearance, and diagnosis of the disease are more common in children who are younger than 5 years. The causes of these variations between countries are unknown, but they predicted that environmental factors can affect. ${ }^{7}$
Atkinson et al. mentioned in their study that T1DM is more common in males than females. Moreover, they also reported that the seasons at which the child is born could affect the probability of being affected by T1DM. Children who were born in spring are more liable to have T1DM. In addition, children are more common to be diagnosed with T1DM in the autumn and winter seasons. ${ }^{7}$

The prediction of T1DM incidence will be increasing by about $3-4 \%$ yearly and the onset of the disease will be younger more than previous. ${ }^{19}$

Future wise in 2030, WHO is predicting that the number of diabetic patients to be doubled the previous existing cases since $2000 .^{2-5,26}$

\section{Diagnostic Tests of Diabetes Mellitus}

Multiple diagnostic tests can be done to diagnose DM such as fasting plasma glucose $(\geq 7.0 \mathrm{mmol} / \mathrm{L})$, hemoglobin A1c (HbA1c) ( $\geq 6.5 \%), 2$ hours plasma glucose in $75 \mathrm{~g}$ of oral glucose tolerance test $(\geq 11.1 \mathrm{mmol} / \mathrm{L})$, or random plasma glucose $(\geq 11.1 \mathrm{mmol} / \mathrm{L}){ }^{4,7,27}$ Two laboratory tests should be done on two different days for the confirmation in symptomless patients who are susceptible to have diabetes. It is better to be the same type of test unless a random blood glucose test was selected.

On the other hand, a single laboratory test is enough to confirm diabetes in patients with hyperglycemia symptoms. Early intervention in young patients who expresses symptoms of hyperglycemia is very important even before reaching the full diagnosis to prevent worsening the condition. ${ }^{4}$

Each type of blood glucose test has pros and cons. Despite $\mathrm{HbA1c}$ being considered less sensitive than other types of tests and it gives disingenuous results in patients with several conditions (such as hemoglobinopathies, iron deficiency anemia, Graves' disease, hepatic diseases, and renal diseases), it has several advantages. One of these advantages it can test blood glucose levels at any time of the day. Second, it is more acceptable than other traditional types of tests such as fasting blood glucose or 2 hours plasma glucose test. Third, avert changeable reading from 1 day to another. Lastly, it elucidates the individual's condition for 2-3 months. Also, a validated assay standardized program should be used with $\mathrm{HbA1c}$ to have reliable results. On the other hand, one of the disadvantages of $\mathrm{HbA1c}$ test is that the normal reading will vary from race to another, e.g., the normal value of HbA1c in African and Indian Americans, Hispanics, and Asian is higher than none Hispanics individuals by $0.4 \%$, which mean that Hispanic individuals were less common to be diagnosed with diabetes than other races. In addition, the $\mathrm{HbA1c}$ value can be affected by the age of the individuals, every decay can increase the value of $\mathrm{HbA1c}$ by $0.1 \%$. In conclusion, choosing the type of test that should be used to test the blood glucose level for each individual depends on clinical judgment. ${ }^{4}$

The grade of blood glucose level can be variable with time. Diabetes mellitus can be existing but without a change in the blood glucose level which is controlled diabetes. On the other hand, the same disease can progress and cause impaired fasting glucose (IFG) and/or impaired glucose tolerance (IGT) which is the uncontrolled type. By reducing the weight, exercising, and using oral medications diabetic patients can move toward the controlled side of diabetes and can live without the need for manufactured insulin. Other patients who have insufficient insulin secretion might need insulin 
supplements, but they can live without it. In contrast, patients who have destructed ß-cells and complete absence of natural insulin production will need insulin replacement throughout their life. ${ }^{5}$

\section{Type 1 Diabetes Mellitus}

Juvenile diabetes or insulin-dependent diabetes, also called T1DM, was known to be a chronic autoimmune childhood disorder. It is considered an immune-associated or immune-mediated disease. ${ }^{5,6}$ It is highly dependent on insulin secretion that results from improper and dysfunctional pancreatic $ß$-cells that are responsible for insulin hormone production..$^{5,6,28,29}$ Devastation speed of $ß$-cells are varying from one person to another. $ß$-cells destruction is considered fast in children and adolescent patients compared to adults. Wherefore, many young patients can be exposed to ketoacidosis conditions as a first demonstration of the disease. Contradictory, other patients who have some functioning ß-cells can have a slower pace of symptoms appearance and this might prohibit them from being in the ketoacidosis stage for many years. ${ }^{5,16}$

On the other hand, many studies suggested that there are subcategories of T1DM depending on the presence of autoantibodies. Type $1 \mathrm{~A}$ diabetes known as autoimmune T1DM represents $70-90 \%$ of T1DM patients. The other type is type 1B diabetes, called idiopathic T1DM which is less common than type $1 \mathrm{~A}$. In type $1 \mathrm{~B}$ diabetes, autoantibodies do not exist in this subcategory and the cause of it is not clear yet. Despite these subcategories, the terminology of type $1 \mathrm{~A}$ and type $1 \mathrm{~B}$ is not routinely utilized. ${ }^{7}$

Robert et al. presented in their recent review that T1DM is responsible to decrease an individual's life expectancy by 12 years in comparison to a healthy individual. ${ }^{16}$

Moreover, multiple genetic and environmental factors have an impact on $ß$-cells destruction but this fact is still not clear yet. ${ }^{5} \mathrm{~A}$ lot of genetic disorders (up to 40 loci) showed to have a responsibility in causing T1DM. ${ }^{7}$ Multiple genetic and environmental corresponding factors are believed to be the major causes of DM such as enterovirus (Coxsackievirus type B), time and number of exposures to cow's milk, long-term breastfeeding, and reduced blood level of vitamin D. Other similar factors include premature birth and maternal age. ${ }^{28}$ In contrast, a study conducted by Cherian et al. showed that there is no strong correlation between these genetic and environmental factors and the incidence of type 1 diabetes. ${ }^{21}$ On the other hand, other studies reported that the reason for T1DM is unexplored., ${ }^{4,16}$

This type of diabetes represents only $5-10 \%$ of all types of diabetes. Eighty-five percent to $90 \%$ of T1DM patients have one or more diabetic biomarkers of immune destruction of $ß$-cells in their fasting blood test such as islet cell autoantibodies, autoantibodies to insulin, autoantibodies to glutamic acid decarboxylase (GAD), and autoantibodies to tyrosine phosphatase-related islet antigen (IA-2) and (IA-2B). ${ }^{5}$

Anciently, T1DM was strictly the disease of young children and teens, but this fact is no longer considered as a risk factor. On the other hand, polydipsia, polyphagia, polyuria, and the use of external insulin lifelong are considered strong indicators for T1DM. ${ }^{7}$ Type 1 DM could occur in children and adults, but it is more common in children. The onset of symptoms of the disease mostly starts at the age of 5-7 years or puberty when the hormones antagonize the action of insulin. ${ }^{7,16}$
Patients with T1DM are 10 times more susceptible to have cardiovascular diseases (such as myocardial infarction, stroke, and angina) compared to healthy individuals. Following intensive diabetic treatment, these complications can be decreased up to $42 \%$ comparing to traditional diabetic treatments. ${ }^{7}$

\section{Pathogenesis}

At the beginning of the incidence of T1DM, multiple cells in pseudoatrophic islets can be present such as cells producing glycogen, somatostatin, and pancreatic ploy-peptide. In addition, normal islets and islets containing b-cells, lymphocytes, and monocytes can also be present. According to these heterogeneous islets, the pathogenesis of T1DM is considered complicated. ${ }^{3}$

In an animal study, they found that inserting CD4 cells that are derived from T1DM mice can produce T1DM in non-diabetic mice, which indicates that CD4 cells availability represents a precondition for establishing T1DM. On the other hand, the presence of a cluster of differentiation 8 (CD8) can play an important role in controlling the amount of damage only. So, the presence of CD4 is considered the only cell that can be described as the most important marker of T1DM. Moreover, type 1 Thelper (Th-1) and interferon-g was found to be the cause of macrophages stimulation which is responsible to cause $ß$-cells alteration and increase the risk of insulin inhibition. ${ }^{3}$

\section{Pathophysiology}

There is controversy regarding the pathophysiology of T1DM. Many studies supported that there are two perceptions of the cause of diabetes. First, the existence of chronic inflammatory islets (insulitis) that affect the pancreas which is present at the initial onset of diabetes's symptoms. Second, in the chronic stage of T1DM, lacking insulin-formation cells in the pancreas make the pancreas incapable to form insulin. Other studies stated that there are sequences of functional disfigurement in bone marrow, thymus, and ß-cells that accordingly subsidize in causing T1DM. ${ }^{7}$

The devastation of $ß$-cells as a result of autoantibodies is responsible to reduce the amount of insulin which causes metabolic disturbances that are correlated with T1DM. Also, the destruction of $ß$-cells can affect a-cells that are present in the pancreas which leads to increased excretion of glucagon in T1DM individuals. This mechanism is contrary to what happens in healthy individuals. Increase blood glucose levels in well-fit individuals will decrease the amount of glucagon excretion. However, increased glucagon secretion in T1DM will aggravate metabolic disturbances that occur due to low insulin secretion. Disturbance in lipid destruction that occurs due to insulin deficiency in T1DM leads to an increase in the level of free fatty lipid in the plasma which represses glucose metabolism in the peripheral tissues (e.g., skeletal muscle). Low insulin secretion and suppression of glucose metabolism will cause interpretation impairment of some genes that are responsible to mark specific tissues to react normally to insulin such as glucokinase in the liver and GLUT 4 class of glucose transporters in adipose tissue.

Improper metabolic function of glucose, lipid, and protein is the most metabolic disturbance that occurs with T1DM. ${ }^{3}$

\section{Effect of Type 1 Diabetes Mellitus on Oral Health}

Diabetes mellitus mainly affect organs and tissues that are affluent with blood vessels including kidneys, eyes, and nerves. Adding to that, the oral cavity is covered with epithelial tissues that are rich in small blood vessels. ${ }^{11}$ 
Several oral signs and symptoms are associated with DM, including low salivary flow rate, dental decay, gingival and periodontal diseases, oral lesions such as candidiasis and oral lichen planus, burning sensation, altered taste, geographic and fissured tongue, and impaired wound healing. ${ }^{8-10}$

\section{Oral Hygiene, Gingival, and Periodontal Health}

Many studies reported that there is a strong correlation between T1DM and gingival and periodontal diseases and these periodontal diseases begin to appear when the child reaches pubertal age. While Lalla et al. in their study concluded that periodontal diseases can start at an early age (6-11 years). ${ }^{30}$ Many studies suggested that one of the reasons for periodontal disease is the metabolic disturbances that occur in specific tissues which leads to a decrease in the defence mechanism against infection and will lead to periodontal diseases. ${ }^{11}$
On the other hand, there are contradictory studies concerning the relationship between oral hygiene, gingivitis and periodontitis, and T1DM as summarized in Table 2 .

\section{Teeth Shedding and Eruption}

Generally, there are confined studies related to dentition and teeth eruption, and these studies are not compatible. ${ }^{11}$ Alteration in teeth eruption sequence might have multiple disadvantages including crowding, teeth malalignment, difficulty in maintaining good oral hygiene that can cause gingivitis and periodontitis, which will necessitate orthodontic treatment. The activity of osteoclasts, root formation, nourishment, and hormonal changes can influence teeth eruption, but the main cause of alteration in eruption is still unclear yet. ${ }^{13}$ Adler et al. found that children with T1DM with age younger than 11.5 years had teeth eruption acceleration, while children older than 11.5 years had delayed teeth eruption process. ${ }^{12}$

Table 2: Studies concerning the relationship between type 1 diabetes mellitus (T1DM) and oral health

\begin{tabular}{|c|c|c|c|}
\hline Study & Year & Materials and methods & Results \\
\hline Lalla et al. ${ }^{30}$ & 2007 & $\begin{array}{l}\text { - Patients were divided into two groups according } \\
\text { to their health status (diabetic and healthy). } \\
\text { - Periodontal health was evaluated by examining } \\
\text { plaque accumulation and gingival health using } \\
\text { Silness and Löe index, along with the probing } \\
\text { depth using a periodontal probe and evaluating } \\
\text { the clinical attachment loss. }\end{array}$ & $\begin{array}{l}\text { Periodontitis was more common in T1DM in } \\
\text { comparison to healthy patients. }\end{array}$ \\
\hline Orbak et al. ${ }^{11}$ & 2008 & $\begin{array}{l}\text { Patients were divided into two groups according } \\
\text { to their health status (diabetic and healthy). } \\
\text { - Plaque and gingival health were examined using } \\
\text { Silness and Löe index. }\end{array}$ & $\begin{array}{l}\text { Plaque accumulation, gingivitis, and } \\
\text { periodontist were more common in } \\
\text { T1DM in comparison to healthy patients. }\end{array}$ \\
\hline Alamoudi et al. ${ }^{31}$ & 2013 & $\begin{array}{l}\text { - Patients were divided into two groups according } \\
\text { to their health status (diabetic and healthy). } \\
\text { - Amount of plaque accumulation, gingival health, } \\
\text { and periodontal health was examined. } \\
\text { - Plaque was calculated by examining } 3 \text { tooth } \\
\text { surfaces which are midbuccal, mesiobuccal, and } \\
\text { lingual. } \\
\text { - Calculus and gingival examinations were done } \\
\text { using Green and vermillion and Silness and Löe } \\
\text { indices, respectively. }\end{array}$ & $\begin{array}{l}\text { Periodontitis was more common in T1DM } \\
\text { patients compared to healthy individuals. } \\
\text { No significant difference was found between } \\
\text { diabetic and healthy individuals in plaque } \\
\text { index, gingival index, and bleeding upon } \\
\text { probing. }\end{array}$ \\
\hline Carneiro et al. ${ }^{32}$ & 2015 & $\begin{array}{l}\text { Diabetic patients were classified into three } \\
\text { groups according to the mean of } \mathrm{HbA1c} \text { in } 3 \text { years } \\
\text { (group I: } \mathrm{HbA} 1 \mathrm{c} \leq 8 \% \text {, group II: } \mathrm{HbA} 1 \mathrm{c}>8 \% \text {, and } \\
\leq 10 \% \text { and group III: HbA1c }>10 \% \text { ). } \\
\text { - Gingival and periodontal health were examined } \\
\text { using simplified oral hygiene index }(\mathrm{OHI}-\mathrm{S} \text { ) and } \\
\text { Community Periodontal Index (CPI), respectively. }\end{array}$ & $\begin{array}{l}\text { Gingivitis and periodontitis were more com- } \\
\text { mon in patients with } \mathrm{HbA} 1 \mathrm{c}>10 \% \text {. }\end{array}$ \\
\hline Wyne et al. ${ }^{29}$ & 2016 & $\begin{array}{l}\text { - Patients were divided into two groups according } \\
\text { to their health status (diabetic and healthy). } \\
\text { - Gingival and periodontal health were examined. } \\
\text { - Oral hygiene was classified into good, poor, } \\
\text { and fair. } \\
\text { - Gingival health was classified into normal, mild, } \\
\text { moderate, profound, and very severe gingival } \\
\text { disease. }\end{array}$ & $\begin{array}{l}\text { No differences between healthy and diabetes } \\
\text { children in gingival and periodontal health. }\end{array}$ \\
\hline
\end{tabular}




\begin{tabular}{|c|c|c|c|}
\hline Study & Year & Materials and methods & Results \\
\hline Geetha et al. ${ }^{33}$ & 2019 & $\begin{array}{l}\text { - Patients were divided into two groups according } \\
\text { to their health status (diabetic and healthy). } \\
\text { - Periodontal health was examined using the } \\
\text { community periodontal index (CPI). }\end{array}$ & $\begin{array}{l}\text { Periodontitis was more common in T1DM in } \\
\text { comparison to healthy patients. }\end{array}$ \\
\hline Babatzia et al. ${ }^{34}$ & 2019 & $\begin{array}{l}\text { Patients were divided into three groups (poorly } \\
\text { controlled diabetes, well-controlled diabetes, } \\
\text { and healthy). } \\
\text { - Plaque accumulation, gingival health, and } \\
\text { periodontal health were evaluated using Silness } \\
\text { and Löe and Greene and Vermillion indices. }\end{array}$ & $\begin{array}{l}\text { Poorly controlled diabetic patients had more } \\
\text { plaque accumulation in comparison to well- } \\
\text { controlled diabetic and healthy individuals. } \\
\text { No statistically significant differences were } \\
\text { found between the groups in gingival and } \\
\text { periodontal health. }\end{array}$ \\
\hline AlMutairi et al. ${ }^{22}$ & 2020 & $\begin{array}{l}\text { Patients were divided into two groups according } \\
\text { to their health status (diabetic and healthy). } \\
\text { - Oral examination was done using WHO criteria. }\end{array}$ & $\begin{array}{l}\text { No statistically significant difference in oral } \\
\text { health status was found between diabetic } \\
\text { and healthy individuals. }\end{array}$ \\
\hline
\end{tabular}

Another study done by Orbak et al. found that teeth eruption was more rapid in diabetic patients with an age range from 5 to 10 years. ${ }^{11}$ This finding goes in line with the result of Alamoudi et al. which reported that diabetic patients had more teeth eruption acceleration in comparison to healthy individuals in early mixed dentition (5-10 years). ${ }^{31}$ In contrast, the eruption of permanent teeth was more retarded in diabetic patients with an age range from 11 to 14 years. ${ }^{11}$ While another study reported that there was no significant difference between healthy and diabetic individuals in terms of eruption acceleration in the age above 10 years. ${ }^{31}$

Counter to that, a study by Lal et al. revealed that diabetic children with late mixed dentition had teeth eruption acceleration when compared to healthy children. On the other hand, there was no significant difference in teeth eruption between diabetic patients and healthy individuals at early mixed dentition. ${ }^{13}$

\section{Conclusion}

Type 1 DM could occur in children and adults, but it is more common in children. ${ }^{7,16}$ Polydipsia, polyphagia, polyuria, and the use of external insulin lifelong are considered strong indicators for T1DM. ${ }^{7}$ The onset of symptoms of the disease mostly starts at the age of 5-7 years or puberty when the hormones antagonize the action of insulin. 7,16

Diabetes mellitus mainly affect organs and tissues that are affluent with blood vessels including kidneys, eyes, and nerves. Adding to that oral cavity is covered with epithelial tissues that are rich with small blood vessels. ${ }^{11}$ Several oral signs and symptoms are associated with DM, including low salivary flow rate, dental decay, gingival and periodontal diseases, oral lesions such as candidiasis and oral lichen planus, burning sensation, altered taste, geographic and fissured tongue, and impaired wound healing..$^{8-10}$

There are contradictory studies concerning the relationship between oral hygiene, gingivitis and periodontitis, teeth shedding and eruption, and T1DM.

Few studies were carried out in KSA regarding oral hygiene, gingival and periodontal health, and teeth shedding in diabetic children. Further studies are needed to explore the effect of T1DM on oral health in children and adolescents.

\section{Clinical Significance}

Since T1DM is considered one of the most popular diseases in children and adolescents, and it has a major effect on their lifestyle in general and oral health in specific, it is important for the dentists dealing with pediatric diabetic patients to know the most important general findings of those specific patients, as well as the effect of T1DM on children's oral health to set well-established guidelines to reach a high standard of care for those children.

\section{Authors Contributions}

Literature search and studies selection were performed by Rafif Mandura, Omar El Meligy, Moaz Attar, and Rana Alamoudi. Rafif Mandura: provided the research idea and wrote the manuscript. Omar El Meligy: contributed to the design and revised the manuscript. Moaz Attar and Rana Alamoudi: performed contributions to manuscript revisions. All authors have read and approved the final manuscript.

\section{References}

1. Allen EM, Ziada HM, O'Halloran D, et al. Attitudes, awareness and oral health-related quality of life in patients with diabetes. J Oral Rehabil 2008;35(3):218-223. DOI: 10.1111/j.1365-2842.2007. 01760.x.

2. Alrimthi HA, Alsahly KW, Alshahrani AH, et al. Diabetic patients and oral health in Bisha region. Kingdom of Saudi Arabia Pak J Surg 2015;31(3):213-215.

3. Ozougwu O. The pathogenesis and pathophysiology of type 1 and type 2 diabetes mellitus. J Physiol Pathophysiol 2013;4(4):46-57. DOI: 10.5897/JPAP2013.0001.

4. Punthakee Z, Goldenberg R, Katz P, et al. Definition, classification and diagnosis of diabetes, prediabetes and metabolic syndrome. Can J Diabetes 2013;37(Suppl 1):S8-S11. DOI: 10.1016/j.jcjd.2013.01.011.

5. American Diabetes Association. Diagnosis and classification of diabetes mellitus. Diabetes Care 2014;37(Suppl 1):S81-S90. DOI: 10.2337/dc14-S081.

6. Stenberg D. Type 1 diabetes mark. Acta Vet Scand 2015;85(85):21-28.

7. Atkinson MA, Eisenbarth GS, Michels AW. Type 1 diabetes. Lancet 2014;383(9911):69-82. DOI: 10.1016/S0140-6736(13)60591-7.

8. Kudiyirickal MG, Pappachan JM. Diabetes mellitus and oral health. Endocrine 2015;49(1):27-34. DOI: 10.1007/s12020-014-0496-3.

9. Albert DA, Ward A, Allweiss $P$, et al. Diabetes and oral disease: implications for health professionals. Ann NY Acad Sci 2012;1255(1):115. DOI: 10.1111/j.1749-6632.2011.06460.x.

10. American Diabetes Association. Diagnosis and classification of diabetes mellitus. Diabetes Care 2012;35(Suppl 1):S64-S71. DOI: $10.2337 / \mathrm{dc} 12-\mathrm{s} 064$.

11. Orbak R, Simsek S, Orbak Z, et al. The influence of type-1 diabetes mellitus on dentition and oral health in children and adolescents. Yonsei Med J 2008;49(3):357-365. DOI: 10.3349/ymj.2008.49.3.357. 
12. Adler $\mathrm{P}$, Wegner $\mathrm{H}$, Bohatka L. Influence of age and duration of diabetes on dental development in diabetic children. J Dent Res 1973;52(3):535-537. DOI: 10.1177/00220345730520032601.

13. Lal S, Cheng B, Kaplan S, et al. Accelerated tooth eruption in children with diabetes mellitus. Pediatrics 2008;121(5):e1139-e1143. DOI: 10.1542/peds.2007-1486.

14. Shields BM, Peters JL, Cooper C, et al. Can clinical features be used to differentiate type 1 from type 2 diabetes? a systematic review of the literature. BMJ Open 2015;5(11):e009088. DOI: 10.1136/bmjopen2015-009088.

15. Moini J. Epidemiology of diabetes. 1st ed., Florida, USA: Elsevier; 2019. pp. 1-210.

16. Robert AA, Al-Dawish A, Mujammami M, et al. Type 1 diabetes mellitus in Saudi Arabia: a soaring epidemic. Int J Pediatr 2018;2018:1-9. DOI: 10.1155/2018/9408370.

17. Centers for Disease Control and Prevention. National Diabetes Statistics Report: Estimates of diabetes and its burden in the United States. Atlanta, GA: US Department of Health and Human Services; 2014.

18. Patterson C, Guariguata L, Dahlquist G, et al. Diabetes in the young-a global view and worldwide estimates of numbers of children with type 1 diabetes. Diabetes Res Clin Pract 2014;103(2):161-175. DOI: 10.1016/j.diabres.2013.11.005.

19. Al Zahrani AM, Al Shaikh A. Glycemic control in children and youth with type 1 diabetes mellitus in Saudi Arabia. Clin Med Insights Endocrinol Diabetes 2019;12:1179551418825159. DOI: 10.1177/1179551418825159.

20. LaPorte RE, Tuomilehto J, King $\mathrm{H}$. WHO multinational project for childhood diabetes. Diabetes Care 1990;13(10):1062-1068. DOI: 10.2337/diacare.13.10.1062.

21. Cherian MP, Al-Kanani KA, Al Qahtani SS, et al. The rising incidence of type 1 diabetes mellitus and the role of environmental factors three decade experience in a primary care health center in Saudi Arabia. J Pediatr Endocrinol Metab 2010;23(7):685-695. DOI: 10.1515/ jpem.2010.23.7.685.

22. AlMutairi FJ, Pani S, Alrobaie F, et al. Relationship between type-I diabetes mellitus and oral health status and oral health-related quality of life among children of Saudi Arabia. J Fam Med Prim Care 2020;6(2):169-170. DOI: 10.4103/jfmpc.jfmpc_1160_19.
23. Al-Herbish AS, El-Mouzan MI, Al-Salloum AA, et al. Prevalence of type 1 diabetes mellitus in Saudi Arabian children and adolescents. Saudi Med J 2008;29(9):1285-1288.

24. Abduljabbar MA, Aljubeh JM, Amalraj A, et al. Incidence trends of childhood type 1 diabetes in eastern Saudi Arabia. Saudi Med J 2010;31(4):413-418.

25. Habeb AM, Al-Magamsi MS, Halabi S, et al. High incidence of childhood type 1 diabetes in Al-Madinah, North West Saudi Arabia (2004-2009). Pediatr Diabetes 2011;12(8):676-681.DOI: 10.1111/j.13995448.2011.00765.x.

26. Wild S, Roglic G, Green A, et al. Global prevalence of diabetes: estimates for the year 2000 and projections for 2030. Diabetes Care 2004;27(5):1047-1053. DOI: 10.2337/diacare.27.5.1047.

27. Matthews DC. The relationship between diabetes and periodontal disease. J Can Dent Assoc 2002;68(3):161-164.

28. Novotna M, Podzimek S, Broukal Z, et al. Periodontal diseases and dental caries in children with type 1 diabetes mellitus. Mediators Inflamm 2015;2015:379626. DOI: 10.1155/2015/379626.

29. Wyne AH. Caries, oral hygiene and gingival health status in type I diabetic Saudi children. PODJ 2016;36(3):421-426.

30. Lalla $\mathrm{E}$, Cheng B, Lal S, et al. Diabetes mellitus promotes periodontal destruction in children. J Clin Periodontol 2007;34(4):294-298. DOI: 10.1111/j.1600-051X.2007.01054.x.

31. Alamoudi RA, Elhalabi M, Chogle $S$, et al. Oral health status of type 1 diabetic patients in the UAE [abstract]. IADR 2013. Poster session (Reference ID 3858).

32. Carneiro VL, Fraiz FC, Ferreira FM, et al. The influence of glycemic control on the oral health of children and adolescents with diabetes mellitus type 1. Arch Endocrinol Metab 2015;59(6):535-540. DOI: 10.1590/2359-3997000000117.

33. Geetha S, Pramila M, Jain K, et al. Oral health status and knowledge among 10-15 years old type 1 diabetes mellitus children and adolescents in Bengaluru. Indian J Dent Res 2019;30(1):80-86. DOI: 10.4103/ijdr.IJDR_572_17.

34. Babatzia A, Papaioannou W, Stavropoulou A, et al. Clinical and microbial oral health status in children and adolescents with type 1 diabetes mellitus. Int Dent J 2019;70(2):136-144. DOI: 10.1111/ idj.12530. 